\title{
The prevalence of obstructive sleep apnea- hypopnea syndrome-related symptoms and their relation to airflow limitation in an elderly population receiving home care
}

\author{
This article was published in the following Dove Press journal: \\ International Journal of COPD \\ 10 October 2014 \\ Number of times this article has been viewed
}

\author{
Christos F Kleisiaris ${ }^{1}$ \\ Evangelos I Kritsotakis ${ }^{2}$ \\ Zoe Daniil ${ }^{3}$ \\ Nikolaos Tzanakis ${ }^{4}$ \\ Agelos Papaioannou ${ }^{5}$ \\ Konstantinos I \\ Gourgoulianis ${ }^{3}$ \\ 'Department of Nursing, Technological \\ Educational Institute of Crete, \\ Heraklion, Greece; ${ }^{2}$ School of Health \\ and Related Research (ScHARR), \\ University of Sheffield, Sheffield, \\ England; ${ }^{3}$ Respiratory Medicine \\ Department, Medical School, \\ University of Thessaly, Larissa, Greece; \\ ${ }^{4}$ Department of Thoracic Medicine, \\ Medical School, University of Crete, \\ Heraklion, Greece; ${ }^{5}$ Department of \\ Medical Laboratories, Technological \\ Educational Institute of Thessaly, \\ Larissa, Greece
}

Correspondence: Christos F Kleisiaris Lecturer in Primary Care,

Department of Nursing, TEl of Crete

Estavromenos PO 71004, Heraklion,

Crete, Greece

Tel +03028I0 37953 I

Email chrisklisiaris@staff.teicrete.gr
Background: Both airflow limitation and obstructive sleep apnea-hypopnea syndrome (OSAHS)-related symptoms are most prevalent in the elderly population. Previous studies revealed significant associations between OSAHS-related symptoms and obstructive airway diseases in the general population. However, other studies showed that the frequency of OSAHS-related symptoms in patients with obstructive airway diseases decreases after the age of 60 and older.

Aims: To investigate the prevalence of OSAHS-related symptoms (snoring, breathing pauses, and excessive daytime sleepiness [EDS]) and their relations to airflow limitation, for people over 65 years old.

Methods: A full screening spirometry program was performed in a total of 490 aging participants (mean age 77.5 years - range 65-98) who were attending 16 home care settings in central Greece. Airflow limitation was assessed according to the Global Initiative for Chronic Obstructive Lung Disease (GOLD) spirometric criteria $\left(\mathrm{FEV}_{1} / \mathrm{FVC}<70 \%\right)$. The Berlin Questionnaire and the Epworth Sleepiness Scale were used to screen individuals for OSAHS-related symptoms. Bivariate associations were described using odds ratio (OR) with $95 \%$ confidence intervals (CI).

Results: Airflow limitation prevalence was $17.1 \%$ (male $24.2 \%$ and female $9.9 \%$ ) and was strongly related to male gender and smoking status. The prevalence rates of frequent snoring, breathing pauses, and EDS were $28.1 \%, 12.9 \%$, and $11.6 \%$, respectively. However, participants with airflow limitation were less likely to report breathing pauses, frequent snoring, EDS, and obesity. Finally, frequent snoring was significantly more common in males than females.

Conclusion: This study revealed decreased frequency of OSAHS-related symptoms in participants with airflow limitation suggesting that OSAHS-related symptoms and airflow limitation are not related in our elderly population.

Keywords: sleep apnea syndrome, obstructive airway diseases, excessive daytime sleepiness, snoring

\section{Introduction}

The obstructive sleep apnea-hypopnea syndrome (OSAHS) is a condition characterized by different types of respiratory events that occur during sleep. ${ }^{1}$ Clinically, OSAHS is defined by the occurrence of excessive daytime sleepiness (EDS), loud snoring, and witnessed breathing pauses (at least five events of apneas/hypopneas per hour of sleep). Worldwide, the prevalence of the syndrome ranges between $30 \%$ and $80 \%$ for people 
aged 65 years and over, ${ }^{2}$ compared to $2 \%-4 \%$ in middleaged population. ${ }^{3}$ Recent studies have shown that OSAHS has been associated with a number of chronic diseases, such as cardiovascular disease (CVD) and hypertension. ${ }^{4}$ In addition, associations between OSAHS and increased likelihood of vehicle accidents, mainly due to daytime hyper somnolence, ${ }^{5,6}$ and obese women after menopause have also been published. ${ }^{7}$

It has been suggested that elderly patients attending primary care often have higher prevalence rates of hypertension, obesity, and obstructive airway diseases including chronic obstructive pulmonary disease (COPD) and asthma that are associated with sleep apnea syndrome. ${ }^{8,9}$ In the international literature, an association of snoring and breathing pauses in the elderly population with obstructive airway disease has also been reported, ${ }^{10,11}$ but the true figures of this association are conflicting. ${ }^{12,13}$ In Greece, only one study has investigated the frequency of OSAHS-related symptoms in patients with obstructive airway diseases using a spirometry program in the general population, ${ }^{14}$ and no study was performed on elderly people receiving home care.

Consequently the purpose of this study was to estimate the prevalence of OSAHS-related symptoms in an elderly population aged over 65 years old receiving home care in central Greece, and to determine whether these symptoms are related to airflow limitation. The secondary aims of the present study were to investigate a possible epidemiological association and/or differences of OSAHS-related symptoms between males and females with respect to age group and a history of certain comorbidities and obesity.

\section{Material and methods}

\section{Study design}

This cross-sectional study was conducted in 16 home care settings in Thessaly, central Greece, during a 6-month period (January to June 2010). Home care settings provide social, nursing, and medical care to their registered members. These members are mainly elderly people over 65 years old, with a disadvantaged social status and/or a poor family support. Following an invitation by the local municipality authorities, this study recruited these elderly members to participate in a door-to-door screening OSAHS and spirometry program. A total of 518 elderly who attended home care settings in Thessaly were approached and 490 of them (response rate $94.5 \%$ ) completed the study questionnaires and subsequently underwent spirometry measurement after their informed consent. None of the participants had a prior diagnosis for OSAHS.

\section{Study analysis}

OSAHS-related symptoms were assessed using the Berlin Questionnaire, which has been widely used in primary care showing high sensitivity 0.86 and specificity 0.77 for a respiratory disturbance index (RDI $>5) .{ }^{15}$ The Berlin Questionnaire includes questions about snoring and witnessed apneas during sleep (category 1), tiredness or fatigue after sleep (category 2), and history of hypertension and/or obesity (category 3 ). Patients present a high pre-test probability for OSAHS if their responses are positive in two out of the three categories.

Subjective daytime sleepiness was quantified using the Greek version of the Epworth Sleepiness Scale. ${ }^{16}$ The Epworth Sleepiness Scale summary score ranges between 0 and 24 and a score greater than 10 is indicative of EDS. ${ }^{17}$

Obesity was defined according to the World Health Organization recommendations (body mass index $\left.[\mathrm{BMI}] \geq 30 \mathrm{~kg} / \mathrm{m}^{2}\right) .{ }^{18}$ History of hypertension, CVDs, and stroke were documented from patients' medical files. Demographic data were also recorded in a structured questionnaire and included gender, age, education, occupation before pension, and smoking status. Two age groups were defined, 65-79 and more than 80 years old, following the current cut-point of life expectancy for the Greek population in the year 2009 (males 79 and females 81 years old). ${ }^{19}$

Airflow limitation diagnosis was based on spirometry. Spirometric tests were performed by a trained technician using the turbine flow spirometer (Pony FX, Cosmed, Rome, Italy), following the American Thoracic Society and European Respiratory Society standards, ${ }^{20}$ and airflow limitation was diagnosed when the post-bronchodilatation ratio of $\mathrm{FEV}_{1}$ to $\mathrm{FVC}$ was less than $70 \%$ predicted $\left(\mathrm{FEV}_{1} / \mathrm{FVC}<70 \%\right)$. A qualified pulmonologist interpreted the spirometric data and made the final diagnosis of airflow limitation using the Global Initiative for Chronic Obstructive Lung Disease (GOLD) criteria. ${ }^{21}$

\section{Ethics committee}

The study was conducted as a part of the clinical development of medical interventions in primary care, and therefore meets the written ethical approval by the Scientific Council of Medical Department - University of Thessaly (Pr No 5740-7th/October 15, 2008). All participants gave informed consent, after a detailed briefing by the researchers for the purpose and procedures of study, while underlining that their participation was voluntary.

\section{Statistical analysis}

Differences of prevalence rates between different patient groups were examined using chi-square tests and binary 
logistic regression, and presented as odds ratios (OR) with 95\% confidence interval (CI). Comparisons between continuous variables were performed by Mann-Whitney UTest. For the evaluation of possible associations between obesity and OSAHS-related symptoms with respect to gender, airflow limitation, hypertension, CVD, and stroke, logistic regression was also applied. All reported $P$-values were two-tailed, and a $P$-value $<0.05$ was considered statistically significant. Data were analyzed using the STATA software package (StataCorp 2011. Stata Statistical Software: Release 12. StataCorp LP, College Station, TX, USA).

\section{Results}

The internal consistencies of the Berlin Questionnaire and the Epworth Sleepiness Scale (Cronbach-alpha, 0.69 and 0.77 , respectively), were considered sufficient to proceed to the statistical analysis.

Table I Demographic data of the study participants

\begin{tabular}{|c|c|c|}
\hline Characteristic & $\mathbf{N}$ & Prevalence (\%) \\
\hline Sex & 490 & \\
\hline Male & 248 & 50.6 \\
\hline Female & 242 & 49.4 \\
\hline Age (years) & $77.5 \pm 6.9$ & \\
\hline $65-79$ & 314 & 64.1 \\
\hline$\geq 80$ & 176 & 35.9 \\
\hline \multicolumn{3}{|l|}{ Smoking status } \\
\hline Current & 44 & 9.0 \\
\hline Former & 138 & 28.2 \\
\hline Never & 308 & 62.9 \\
\hline BMI & Mean $29.7 \pm 5.3$ & \\
\hline Obesity (BMI $\geq 30$ kg/m²) & 217 & 44.3 \\
\hline \multicolumn{3}{|l|}{ OSAHS-related symptoms } \\
\hline Breathing pauses ${ }^{\mathrm{a}}$ & 31 & 6.3 \\
\hline $\mathrm{EDS}^{\mathrm{b}}$ & 57 & 11.6 \\
\hline Frequent snoring ${ }^{c}$ & 130 & 28.1 \\
\hline \multicolumn{3}{|l|}{ Chronic comorbid diseases } \\
\hline Hypertension & 257 & 52.4 \\
\hline $\mathrm{CVD}^{d}$ & 172 & 35.1 \\
\hline Stroke & 24 & 4.9 \\
\hline \multicolumn{3}{|l|}{ Airflow limitation (GOLD) } \\
\hline$(\mathrm{FEV} / \mathrm{FVC}<70 \%)$ predicted & 84 & 17.1 \\
\hline Stage I ( $\left.\mathrm{FEV}_{1} \geq 80 \%\right)$ & 25 & 5.1 \\
\hline Stage II (FEV, $50 \%-79 \%)$ & 38 & 7.7 \\
\hline Stage III (FEV, 30\%-49\%) & 16 & 3.3 \\
\hline Stage IV $(\mathrm{FEV},<30 \%)$ & 5 & 1.0 \\
\hline
\end{tabular}

Notes: Prevalence was given as actual numbers of patients $(\mathrm{N})$ and percentages (\%). aPatients witnessed apnoeas "almost every day" or "3-4 times a week"; ${ }^{\text {bEpworth }}$ Sleepiness Scale - score (ESS $\geq 10$ ); "patients snoring "almost every day" or "3-4 times a week"; includes congestive: heart failure, coronary artery disease, and arrhythmias.

Abbreviations: BMI, body mass index; CVD, cardiovascular disease; EDS, excessive daytime sleepiness; GOLD, Global Initiative for Chronic Obstructive Lung Disease; OSAHS, obstructive sleep apnea-hypopnea syndrome; $\mathrm{FEV}_{1} / \mathrm{FVC}$, forced expiratory volume in I second /forced vital capacity.
In Table 1 we present the main participant characteristics. Mean age did not differ between males and females $(P=0.085)$. Among the study participants, the prevalence rates of OSAHSrelated symptoms (breathing pauses, EDS, and frequent snoring) were $6.3 \%, 11.6 \%$, and $28.1 \%$, respectively. The frequency of obesity was $44.3 \%$ among the study participants.

The prevalence of airflow limitation and distribution of OSAHS-related symptoms between gender and age are presented in Table 2. A history of stroke was not different between the two genders $(4.8 \%$ versus $5.0 \%$, respectively, $P=0.951)$. Males reported a history of CVDs more frequently than females $(40.7 \%$, versus $29.3 \%, P<0.001)$, while for a history of hypertension the situation was reversed (47.6\% versus $57.4 \%, P<0.001)$.

Logistic regression revealed that patients with airflow limitation were significantly more likely to be males $(\mathrm{OR}=2.9$; 95\% CI: $1.74-4.84, P<0.001$ ), current smokers (OR =3.76; CI: $1.82-7.79, P<0.001$ ) or former smokers (OR =2.84; CI: $1.69-4.79, P<0.001)$. The prevalence of airflow limitation was higher in non-obese compared to obese participants $(19.4 \%$ versus $14.3 \%)$, but the difference was not statistically significant $(P=0.135)$. However, participants with airflow limitation had lower mean BMI compared to those without $(28.4 \pm 4.8$ versus 29.9 $\pm 5.3, P=0.034$ ), while a significant trend towards decreasing prevalence of airflow limitation with increasing BMI was noted $\left(\chi^{2}\right.$ test for linear trend, $P=0.047$ ). Of the participants finally diagnosed with airflow limitation in this study, only $25 \%$ had a prior diagnosis of airflow limitation.

\section{Sleep-related symptoms and obesity in patients with and without airflow limitation}

Participants with airflow limitation were less likely to report breathing pauses $(\mathrm{OR}=0.7$; 95\% CI: $0.24-2.06, P=0.518)$, frequent snoring ( $\mathrm{OR}=0.98$; CI: $0.57-1.66, P=0.94)$, and EDS (OR $=0.65$; CI: $0.28-1.48, P=0.303$ ). These findings were reported while participants with airflow limitation were also unlikely to be obese than those without $(\mathrm{OR}=0.69$; CI: $0.43-1.12, P=0.135)$. However, none of these associations were statistically significant - (Figure 1).

\section{Sleep-related symptoms and obesity in patients with a history of hypertension, CVD, and stroke}

A history of hypertension was not associated with frequent snoring $(\mathrm{OR}=1.03$; CI: $0.69-1.55, P=0.883)$, breathing pauses $(\mathrm{OR}=1.11 ; \mathrm{CI}: 0.53-2.31, P=0.783)$, and EDS $(\mathrm{OR}=1.28$; CI: $0.73-2.43, P=0.382)$. However, participants 
Table 2 Distribution of responses according to sex and age

\begin{tabular}{|c|c|c|c|c|c|c|c|c|c|c|c|c|}
\hline \multirow[t]{2}{*}{ Age groups } & \multicolumn{6}{|c|}{ Males } & \multicolumn{6}{|c|}{ Females } \\
\hline & \multicolumn{2}{|c|}{$65-79$} & \multicolumn{2}{|c|}{$\geq \mathbf{8 0}$} & \multicolumn{2}{|c|}{ Total } & \multicolumn{2}{|c|}{$65-79$} & \multicolumn{2}{|c|}{$\geq \mathbf{8 0}$} & \multicolumn{2}{|c|}{ Total } \\
\hline \multicolumn{13}{|c|}{ Obesity $\left(\mathrm{BMI} \geq 30 \mathrm{~kg} / \mathrm{m}^{2}\right)$} \\
\hline Yes & 58 & $39.7 \%$ & 29 & $28.4 \%$ & 87 & $35.1 \%$ & 97 & $57.7 \%$ & 33 & $44.6 \%$ & 130 & $53.7 \%$ \\
\hline No & 88 & $60.3 \%$ & 73 & $71.6 \%$ & 161 & $64.9 \%$ & 71 & $42.3 \%$ & 41 & $55.4 \%$ & 112 & $46.3 \%$ \\
\hline \multicolumn{13}{|c|}{ Breathing pauses } \\
\hline$Y_{e s}^{a}$ & 8 & $5.5 \%$ & 7 & $6.9 \%$ & 15 & $6.0 \%$ & 12 & $7.1 \%$ & 4 & $5.4 \%$ & 16 & $6.6 \%$ \\
\hline No & 138 & $94.5 \%$ & 95 & $93.1 \%$ & 233 & $94.0 \%$ & 156 & $92.9 \%$ & 70 & $94.6 \%$ & 226 & $93.4 \%$ \\
\hline \multicolumn{13}{|l|}{ EDS } \\
\hline$E S S \geq 10$ & 15 & $10.3 \%$ & 16 & $15.7 \%$ & 31 & $12.5 \%$ & 14 & $8.3 \%$ & 12 & $16.2 \%$ & 26 & $10.7 \%$ \\
\hline ESS $<9$ & $|3|$ & $89.7 \%$ & 86 & $84.3 \%$ & 217 & $87.5 \%$ & 154 & $91.7 \%$ & 62 & $83.8 \%$ & 216 & $89.3 \%$ \\
\hline \multicolumn{13}{|c|}{ Frequent snoring } \\
\hline$Y_{e s}{ }^{b}$ & 52 & $35.6 \%$ & 29 & $18.2 \%$ & 81 & $33.1 \%$ & 37 & $24.4 \%$ & 13 & $18.6 \%$ & 50 & $22.6 \%$ \\
\hline No & 94 & $64.4 \%$ & 70 & $81.8 \%$ & 164 & $76.9 \%$ & 115 & $75.6 \%$ & 77 & $81.4 \%$ & 192 & $77.4 \%$ \\
\hline \multicolumn{13}{|c|}{ History of hypertension } \\
\hline Yes & 67 & $45.9 \%$ & 51 & $50.0 \%$ & 118 & $47.6 \%$ & 93 & $55.4 \%$ & 46 & $62.2 \%$ & 139 & $57.4 \%$ \\
\hline No & 79 & $54.1 \%$ & 51 & $50.0 \%$ & 130 & $52.4 \%$ & 75 & $44.6 \%$ & 28 & $37.8 \%$ & 103 & $42.6 \%$ \\
\hline \multicolumn{13}{|c|}{ History of CVD } \\
\hline Yes & 57 & $39.0 \%$ & 44 & $43.1 \%$ & 101 & $40.7 \%$ & 48 & $28.6 \%$ & 23 & $31.1 \%$ & 71 & $29.3 \%$ \\
\hline No & 89 & $61.0 \%$ & 58 & $56.9 \%$ & 147 & $59.3 \%$ & 120 & $71.4 \%$ & 51 & $68.9 \%$ & 171 & $70.7 \%$ \\
\hline \multicolumn{13}{|c|}{ History of stroke } \\
\hline Yes & 8 & $5.5 \%$ & 4 & $3.9 \%$ & 12 & $4.8 \%$ & 12 & $7.1 \%$ & 0 & $0.0 \%$ & 12 & $5.0 \%$ \\
\hline No & 138 & $94.5 \%$ & 98 & $96.1 \%$ & 236 & $95.2 \%$ & 156 & $92.9 \%$ & 74 & $100 \%$ & 230 & $95.0 \%$ \\
\hline \multicolumn{13}{|c|}{ Airflow limitation } \\
\hline Yes & 36 & $24.7 \%$ & 24 & $23.5 \%$ & 60 & $24.2 \%$ & 12 & $7.1 \%$ & 12 & $16.2 \%$ & 24 & $9.9 \%$ \\
\hline No & 110 & $75.3 \%$ & 78 & $76.5 \%$ & 188 & $75.8 \%$ & 156 & $92.9 \%$ & 62 & $83.8 \%$ & 218 & $90.1 \%$ \\
\hline
\end{tabular}

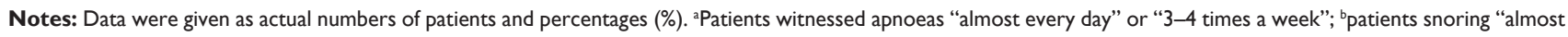
every day" or "3-4 times a week".

Abbreviations: BMI, body mass index; CVD, cardiovascular disease; EDS, excessive daytime sleepiness; ESS, Epworth Sleepiness Scale.

with a history of hypertension were significantly more likely to be obese (OR $=1.61 ; \mathrm{CI}: 1.12-2.3, P=0.010$ ).

No significant difference in OSAHS-related symptoms between patients with CVD and those without CVD was found. In particular, elderly patients with a history of CVD were less likely to report breathing pauses $(\mathrm{OR}=0.74$; CI: $0.33-1.65, P=0.466)$, EDS (OR $=0.92$; CI: 0.51-1.64, $P=0.77$ ), and to be obese ( $\mathrm{OR}=0.89$; $\mathrm{CI}: 0.61-1.3, P=0.546$ ), whereas these patients were more likely to report frequent snoring (OR $=1.36$; $C I$ : $0.9-2.06, P=0.149)$ than elderly patients without CVD.

We also found no significant difference in OSAHSrelated symptoms between patients with stroke compared to those without stroke. Particularly, participants with a history of stroke were less likely to report frequent snoring $(\mathrm{OR}=0.66$; CI: $0.24-1.81, P=0.442)$ and $\mathrm{EDS}(\mathrm{OR}=0.68$; CI: $0.15-2.99, P=0.607)$ than participants without stroke history. However, stroke patients were more likely to report breathing pauses $(\mathrm{OR}=1.37$; $\mathrm{CI}$ : $0.31-6.11, P=0.680)$ and to be obese (OR $=1.27$; CI: $0.56-2.89, P=0.564)$ than patients without stroke history, but these differences were also not significant.

\section{Sleep-related symptoms and obesity between genders}

EDS and frequent snoring were more frequent in males than females (OR $=1.18$; CI: $0.68-2.07, P=0.544$ and $\mathrm{OR}=1.70$; CI: $1.13-2.57, P=0.012$, respectively) although this difference was significant only for frequent snoring. However, males were less likely to report breathing pauses than females $(\mathrm{OR}=0.9$; CI: $0.44-1.88, P=0.798)$. These differences were observed despite the fact that males were less likely to be obese than females (OR =0.47; CI: 0.32-0.67, $P<0.001)$ - Figure 2 .

\section{Sleep-related symptoms and obesity between age groups}

Participants aged 80 years old and over were significantly more likely to report EDS (OR $=1.86$; CI: $1.06-3.24, P=0.029$ ) than those aged 65-79 years old, and were less likely to report breathing pauses and frequent snoring $(\mathrm{OR}=0.98$; CI: 0.46-2.10, $P=0.958$, and OR $=0.77$; CI: $0.50-1.90, P=0.247$, respectively) than participants aged $65-79$ years old. Also, older participants $(80+)$ were less obese $(\mathrm{OR}=0.56$; $\mathrm{CI}$ : $0.38-0.81, P=0.003$ ) than the younger ones $-($ Figure 3 ). 


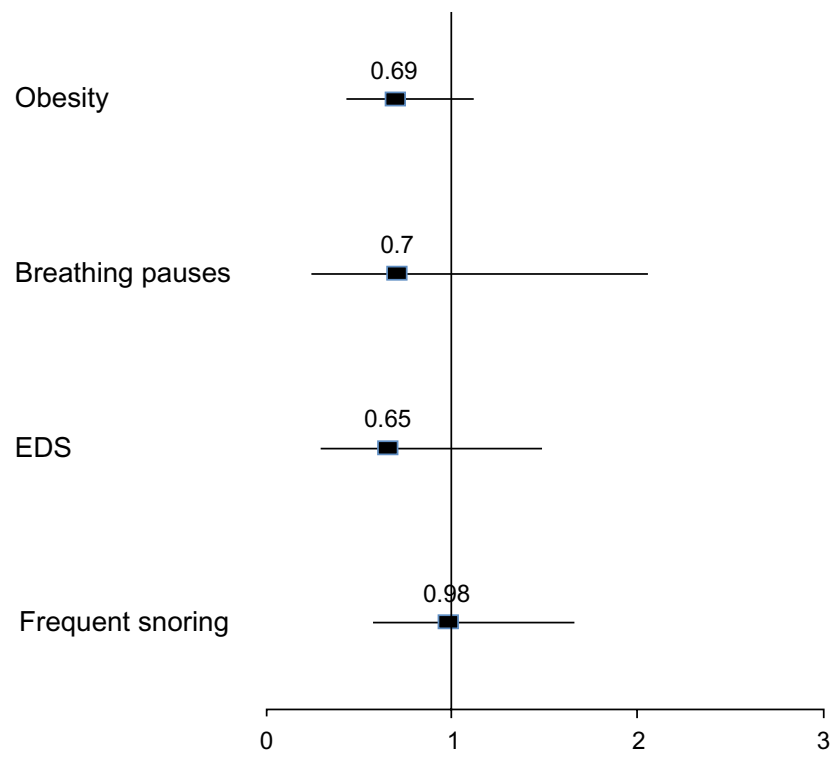

Figure I Comparisons between patients with and without airflow limitation with regard to OSAHS-related symptoms and obesity.

Notes: An OR >I indicates greater likelihood for patients with airflow limitation. Bars represent $95 \%(\mathrm{Cl})$.

Abbreviations: OSAHS, obstructive sleep apnea-hypopnea syndrome; $\mathrm{Cl}$, confidence interval; EDS, excessive daytime sleepiness; OR, odds ratio.

\section{Discussion}

In this cross-sectional study we found that the OSAHS-related symptoms did not differ between patients with and without airflow limitation. Particularly, the elderly participants with airflow limitation presented lower prevalence rates of EDS, breathing pauses, frequent snoring, and obesity than those

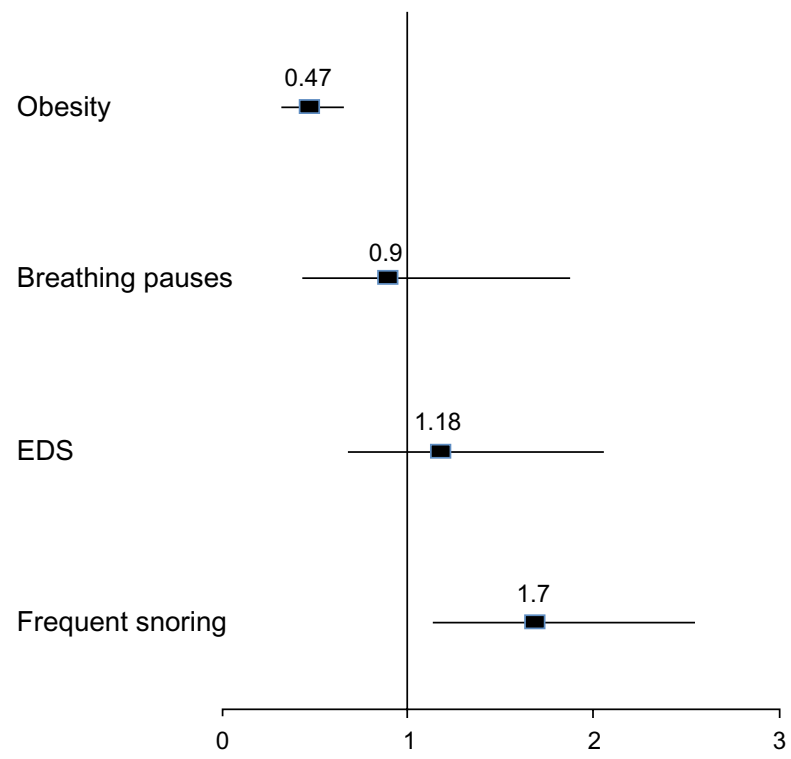

Figure 2 Comparisons between male and female patients with regard to OSAHSrelated symptoms and obesity.

Notes: An OR > I indicates greater likelihood for males. Bars represent $95 \%$ (Cl). Abbreviations: OSAHS, obstructive sleep apnea-hypopnea syndrome; $\mathrm{Cl}$, confidence interval; EDS, excessive daytime sleepiness; OR, odds ratio.

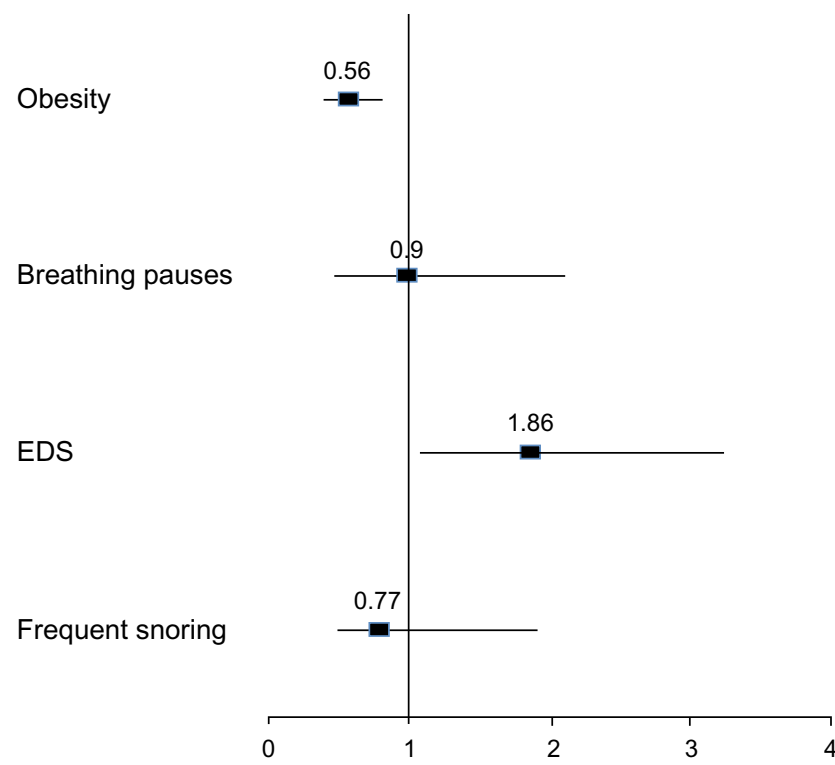

Figure 3 Diferences between the two age groups with regard to OSAHS-related symptoms and obesity.

Notes: An OR > I indicates greater likelihood for people aged $>80$ years old. Bars represent $95 \%(\mathrm{Cl})$.

Abbreviations: OSAHS, obstructive sleep apnea-hypopnea syndrome; $\mathrm{Cl}$, confidence interval; EDS, excessive daytime sleepiness; OR, odds ratio.

without, whereas these associations were not significant. However, EDS was significantly reported more often in males than females, and older people aged $>80$ years old than those aged 65-79 years old, while frequent snoring was more prevalent in males. Finally, a history of chronic comorbidities was also not related to sleep-related symptoms.

The main finding of the present study was that our elderly population with airflow limitation was less likely to report OSAHS-related symptoms than the ones without airflow limitation, while these relations were not significant. In comparison to our results, ${ }^{14}$ a similar study conducted in the same region of Greece in the general population (mean age 60.7 years old), showed increased frequency of OSAHS-related symptoms in COPD and asthma patients, but the associations were significant only for COPD patients. Furthermore, a recent study in Iran also reported significant associations between airflow obstruction and high-risk for OSAHS in the general population, as defined by the Berlin Questionnaire. However, only a small percentage (13.5\%) of the total study sample was more than 60 years old. ${ }^{10}$

Interestingly, several sleep-lab studies supply us with comparative explanations with regard to the occurrence of respiratory events of apnoeas in patients with airflow limitation. Specifically, the Sleep Heart Health Study ${ }^{22}$ has shown that the frequency of the respiratory disturbance index did not differ between participants with and without obstructive airway disease (mean age 66 years old). Similar 
findings were reported by Bednarek et al, ${ }^{23}$ showing that in the general population, the prevalence of airflow obstruction was equal to the prevalence of OSAHS population (AHI/ RDI $>5$ ), whereas only one person over 60 years old was diagnosed with both conditions. Furthermore, Sharma et al, using both the Berlin Questionnaire and polysomnography data, also found that there was no association between $\mathrm{FEV}_{1} \%$ predicted and high-risk of OSAHS. However, the increased OR of OSAHS found in both, COPD and asthma patients were mainly linked to the presence of obesity. ${ }^{12}$

We also found no significant association between EDS and airflow limitation, although EDS was more frequent in elderly men than women and in those patients aged over 80 years old than those aged 65-79 years old. These results are similar to a previous study showing that the presence of EDS was found within the normal limits in patients with chronic hypoxemia and COPD. ${ }^{24}$ In our study, frequent snoring was not related to airflow limitation, in contrast with latest studies. ${ }^{10-14}$ However, data from the Sleep Heart Health Study revealed that habitual snoring prevalence decreases as age increases from 50 to 60 and finally to 70 years old and over, and frequent snoring prevalence also decreases after the age of $65 .{ }^{13-22}$ In our study, older patients ( $>80$ years old) reported less frequent snoring than those of the first age group (65-79 years old), but this difference was not significant. Previous studies in Australian men and Italian women also found no association between frequent snoring and age, while differences were found due to obesity. ${ }^{25,26}$ Since our study population is older compared to other studies, this plausibly explains our decreased prevalence rates of OSAHS-related symptoms in patients with airflow limitation. Numerous community large-population studies, ${ }^{12-22}$ reported that as age increases, the magnitude of these associations for snoring and breathing pauses decreases and becomes less significant after the age of 60 and/or cease to exist. ${ }^{13,27,28}$

It is widely recognized that, OSAHS has been associated with CVD, hypertension, and obesity. ${ }^{1-4}$ However, we did not find significant associations between these comorbidities and sleep-related symptoms, despite the fact that elderly patients with a history of hypertension were more likely to report frequent snoring, breathing pauses, and EDS. Our data are in contrast with Karachaliou et al's findings which showed that hypertension was strongly associated with EDS and frequent snoring, whereas hypertension was not related to breathing pauses. ${ }^{14}$ In our study we showed that hypertension was associated only with obesity. This result is in agreement with a previous brief review which reported that at least part of the association between obesity and hypertension was related to the presence of sleep apnea syndrome. ${ }^{9}$ Moreover, we found that patients with a history of CVD and stroke were less likely to present frequent snoring and EDS. These findings are almost similar to the findings of a Honolulu Heart Program cohort study by Foley et $\mathrm{al}^{29}$ who reported that the diagnoses of CVD and stroke were not associated with habitual snoring, while daytime sleepiness was associated with heart disease. They also found a relation between age and EDS and their ORs were similar to ours. In the present study, patients with a history of stroke were more likely to report breathing pauses. Yaggi and Mohsenin ${ }^{30}$ showed that the presence of OSAHS increases the risk for stroke, while there was evidence that sleep apnea is the actual cause of hypertension, CVD, stroke, and other medical conditions. ${ }^{31}$

Despite the useful findings, our results have certain limitations. Chronic medical diseases such as history of CVDs, hypertension, and stroke were documented from the medical files that may not have been sufficiently completed. For example, there may have been undiagnosed medical conditions that might act as confounders in prevalence of the OSAHS-related symptoms. Furthermore, the OSAHS- related symptoms might be clustered in subgroups of patients with specific airway disease such asthma, COPD, or bronchiectasis. However, the underlying airway disease that could be the cause of airflow limitation has not been investigated in the present study. Another potential limitation of this study is that the results were based on self-reports, whereas polysomnography was not performed. In addition, spirometry according to the American Thoracic Society and European Respiratory Society standards cannot be easily performed on our elderly study participants. In this study, we often needed more than three efforts in order to complete an accepted spirometry test.

\section{Conclusion}

Our data suggest that OSAHS-related symptoms are not related to airflow limitation for people aged over 65 years old. In addition, a lower BMI and advanced age of our sample with airflow limitation possibly contributed to decreased frequency of OSAHS- related symptoms. However, sleep studies are needed to evaluate this assumption. Finally, both airflow limitation and OSAHS remain largely undiagnosed in Greek primary care settings according to our door-to-door spirometry and OSAHS screening program. General Practitioners and health professionals in primary care should perform short screening programs for OSAHS, focused especially on males and obese populations.

\section{Acknowledgments}

All authors would like to thank the elderly participants and employees in home care settings for allowing door-to-door visits in all stages of the survey. 


\section{Author contributions}

All authors contributed toward data interpretation, drafting and revising the paper and agree to be accountable for all aspects of the work.

\section{Disclosure}

All authors declare that there is no financial or personal conflict of interests related to this paper.

\section{References}

1. Lévy P, Tamisier R, Minville C, Launois S, Pépin JL. Sleep apnoea syndrome in 2011: current concepts and future directions. Eur Respir Rev. 2011;20(121):134-146.

2. Epstein LJ, Kristo D, Strollo PJ Jr, et al. Clinical guideline for the evaluation, management and long-term care of obstructive sleep apnea in adults. J Clin Sleep Med. 2009;5(3):263-276.

3. Young T, Peppard PE, Gottlieb DJ. Epidemiology of obstructive sleep apnea: a population health perspective. Am J Respir Crit Care Med. 2002;165(9):1217-1239

4. Hamilton GS, Solin P, Naughton MT. Obstructive sleep apnoea and cardiovascular disease. Intern Med J. 2004;34(7):420-426.

5. Terán-Santos J, Jiménez-Gómez A, Cordero-Guevara J. The association between sleep apnea and the risk of traffic accidents. Cooperative Group Burgos-Santander. N Engl J Med. 1999;340(11):847-851.

6. Torzsa P, Keszei A, Kalabay L, et al. Socio-demographic characteristics, health behaviour, co-morbidity and accidents in snorers: a population survey. Sleep Breath. 2011;15(4):809-818.

7. Bixler EO, Vgontzas AN, Lin HM, et al. Prevalence of sleep-disordered breathing in women: effects of gender. Am J Respir Crit Care Med. 2001;163(3 Pt 1):608-613.

8. Chaouat A, Weitzenblum E, Krieger J, Ifoundza T, Oswald M, Kessler R. Association of chronic obstructive pulmonary disease and sleep apnea syndrome. Am J Respir Crit Care Med. 1995;151(1):82-86.

9. Wolk R, Shamsuzzaman AS, Somers VK. Obesity, sleep apnea, and hypertension. Hypertension. 2003;42(6):1067-1074.

10. Amra B, Golshan M, Fietze I, Penzel T, Welte T. Correlation between chronic obstructive pulmonary disease and obstructive sleep apnea syndrome in a general population in Iran. J Res Med Sci. 2011;16(7):885-889.

11. Larsson LG, Lundbäck B, Jonsson AC, Lindström M, Jönsson E. Symptoms related to snoring and sleep apnoea in subjects with chronic bronchitis: report from the Obstructive Lung Disease in Northern Sweden Study. Respir Med. 1997;91(1):5-12.

12. Sharma B, Feinsilver S, Owens RL, Malhotra A, McSharry D, Karbowitz S. Obstructive airway disease and obstructive sleep apnea: effect of pulmonary function. Lung. 2011;189(1):37-41

13. Young T, Shahar E, Nieto FJ, et al. Predictors of sleep-disordered breathing in community-dwelling adults: the Sleep Heart Health Study. Arch Intern Med. 2002;162(8):893-900
14. Karachaliou F, Kostikas K, Pastaka C, Bagiatis V, Gourgoulianis KI. Prevalence of sleep-related symptoms in a primary care population - their relation to asthma and COPD. Prim Care Respir J. 2007;16(4):222-228.

15. Netzer NC, Stoohs RA, Netzer CM, Clark K, Strohl KP. Using the Berlin Questionnaire to identify patients at risk for the sleep apnea syndrome. Ann Intern Med. 1999;131(7):485-491.

16. Tsara V, Serasli E, Amfilochiou A, Constantinidis T, Christaki P. Greek version of the Epworth Sleepiness Scale. Sleep Breath. 2004;8(2): 91-95.

17. Johns MW. A new method for measuring daytime sleepiness: the Epworth sleepiness scale. Sleep. 1991;14(6):540-545.

18. World Health Organization [homepage on the Internet]. Obesity and overweight, Fact sheet $\mathrm{N}^{\circ} 311$ [updated Aug 2014]. Available from: http://www.who.int/mediacentre/factsheets/fs311/en/. Accessed August 19, 2014.

19. The World Bank [homepage on the Internet]. Life expectancy, World Development Indicators, Public Data. Available from: http://data. worldbank.org/country/greece. Accessed August 19, 2014.

20. Global Initiative for Chronic Obstructive Lung Disease (GOLD). Spirometry for Health Care Providers. GOLD; update 2010. Available from: http://www.goldcopd.org/uploads/users/files/ GOLD_Spirometry_2010.pdf. Accessed August 19, 2014.

21. Global Initiative for Chronic Obstructive Lung Disease (GOLD). Global Strategy for the Diagnosis, Management, and Prevention of Chronic Obstructive Pulmonary Disease. GOLD [updated Jan 2014]. Available from: http://www.goldcopd.org/. Accessed August 19, 2014.

22. Sanders MH, Newman AB, Haggerty CL, et al. Sleep and sleepdisordered breathing in adults with predominantly mild obstructive airway disease. Am J Respir Crit Care Med. 2003;167(1):7-14.

23. Bednarek M, Plywaczewski R, Jonczak L, Zielinski J. There is no relationship between chronic obstructive pulmonary disease and obstructive sleep apnea syndrome: a population study. Respiration. 2005;72(2):142-149.

24. Orr WC, Shamma-Othman Z, Levin D, Othman J, Rundell OH. Persistent hypoxemia and excessive daytime sleepiness in chronic obstructive pulmonary disease (COPD). Chest. 1990;97(3):583-585.

25. Bearpark H, Elliott L, Grunstein R, et al. Snoring and sleep apnea. A population study in Australian men. Am J Respir Crit Care Med. 1995;151(5):1459-1465.

26. Ferini-Strambi L, Zucconi M, Castronovo V, Garancini P, Oldani A, Smirne S. Snoring and sleep apnea: a population study in Italian women. Sleep. 1999;22(7):859-864.

27. Lee W, Nagubadi S, Kryger MH, Mokhlesi B. Epidemiology of Obstructive Sleep Apnea: a Population-based Perspective. Expert Rev Respir Med. 2008;2(3):349-364.

28. Russell T, Duntley S. Sleep disordered breathing in the elderly. Am J Med. 2011;124(12):1123-1126.

29. Foley DJ, Monjan AA, Masaki KH, Enright PL, Quan SF, White LR. Associations of symptoms of sleep apnea with cardiovascular disease, cognitive impairment, and mortality among older Japanese-American men. J Am Geriatr Soc. 1999;47(5):524-528.

30. Yaggi H, Mohsenin V. Obstructive sleep apnoea and stroke. Lancet Neurol. 2004;3(6):333-342.

31. Collop N. The effect of obstructive sleep apnea on chronic medical disorders. Cleve Clin J Med. 2007;74(1):72-78.

International Journal of COPD

\section{Publish your work in this journal}

The International Journal of COPD is an international, peer-reviewed journal of therapeutics and pharmacology focusing on concise rapid reporting of clinical studies and reviews in COPD. Special focus is given to the pathophysiological processes underlying the disease, intervention programs, patient focused education, and self management protocols.

This journal is indexed on PubMed Central, MedLine and CAS. The manuscript management system is completely online and includes a very quick and fair peer-review system, which is all easy to use. Visit http://www.dovepress.com/testimonials.php to read real quotes from published authors. 